\title{
Computationally efficient prediction of canopy level urban air temperature at the neighbourhood scale
}

\begin{abstract}
The Urban Weather Generator (UWG) is a simple and computationally efficient model that predicts canopy level urban air temperature using meteorological information measured at a reference weather station. An evaluation of an improved version of the model, which accounts for different urban morphologies and building usage distributions within a city, is presented in this paper. Calculated urban air temperatures are compared with measurements from a network of weather stations in Singapore, representing a range of land uses, morphological parameters and building usages. The comparison shows a satisfactorily performance of the model for all weather conditions and for different reference weather stations. Singapore is located in a hot and humid climate where vegetation plays a critical role in climate regulation, the urban morphology is very heterogeneous and air-conditioning systems are generally used throughout the year. This makes Singapore an interesting case study in order to analyse the potential and limitations of the model. The study shows that the model can be applied to different climates and urban configurations to obtain an estimation of the Urban Heat Island (UHI) effect. However, the simplifications and assumptions of the model prevent it from capturing very site-specific microclimate effects.
\end{abstract}

Keywords: urban heat island; urban climate; urban canopy model; urban boundary layer; weather prediction; neighbourhood scale

\section{Introduction}

Urban areas are characterized by an increase in air temperature relative to the surrounding undeveloped, rural areas, a phenomenon known as the Urban Heat Island (UHI) effect. The UHI effect has been quantified from meteorological observations carried out in many cities around the world. Recent examples include studies by Roth [1],Hicks et al. [2],Lee and Baik [3],Zhou 
and Shepherd [4],and Houet and Pigeon [5]. The study and prediction of the UHI effect is important in order to integrate climate-sensitive considerations into the decision-making process of urban design and operation [6].

The UHI effect arises mainly from differences in morphology and surface materials of the urban relative to the surrounding rural terrain. The city reduces the diurnal cycle of air temperature due to the presence of more surfaces with large heat capacities, increasing the effective thermal inertia [7]. Furthermore, urban surface roughness decreases the mean wind velocity and reduces the heat removal through convection. Added to this is the heat gain due to anthropogenic sources [8] and lower evaporation due to the reduction of vegetated areas.

Grimmond et al. [9] review the existing modelling approaches to predict the UHI effect, which include statistical and numerical models. Of the latter, microscale computational fluid dynamics (CFD) models are capable of accurately predicting information about the canopy-microscale UHI distribution at a particular location [10]. However, due to their high computational cost, their scope is spatially and temporally limited; thus, typically, these models are not applied to annual calculations or analyses at a scale larger than a few blocks, for example. Furthermore, the accuracy of CFD simulations strongly depends on the boundary conditions, for which detailed information in most cases is not available, and on the treatment of the turbulence closure and radiation. Although CFD simulations can be very useful for specific studies, especially involving distribution of wind speed, a very high computational cost is paid for a gain in accuracy that is not guaranteed.

Mesoscale models are considered state-of-the-art in atmospheric weather prediction and are used as operational and research tools. These models represent the urban canopy as an aerodynamic roughness for which analytical expressions act as a bridge between the surface and the first atmospheric layer. The latest generation of mesoscale models is coupled with urban canopy models [11, 12, 13], improving the representation of the thermal and roughness effects of urban areas on the atmosphere. However, the application of mesoscale models to urban climate predictions, for which the temporal scale of interest ranges from a few days to one year or even a century, is affected by the same limitations as for microscale CFD models.

As an alternative to computationally expensive mesoscale models, Bueno et al. [14] proposed an Urban Weather Generator (UWG) to estimate the UHI effect in the urban canopy layer using meteorological information measured at an operational weather station located in an open area outside the 
city. The UWG is based on energy conservation principles applied to control volumes in the urban canopy layer and the urban boundary layer for which boundary conditions can be imposed (Fig. 1). The model is also a bottomup building stock model [15] that can be used to estimate building energy consumption at the city scale, specifically accounting for the interactions between buildings and the urban environment.

The present study describes an extension of the UWG's capabilities after first reviewing its most important aspects. While the previous version allowed the user to define only one representative urban configuration and building use for a given city, the new version is able to differentiate various neighbourhood characteristics within a city and different building uses within an urban area. As a result, the UWG can now be used to estimate the UHI effect and building energy consumption at neighbourhood resolution. Other changes include the addition of longwave radiation effects of water vapour and carbon dioxide in the urban boundary layer, and a new treatment of the surface roughness on the airflow.

The UWG was originally evaluated against field data from experiments carried out in Basel [16] and Toulouse [17]. Bueno et al. [14] showed that the error of the model stayed within the range of air temperature variability observed in different locations within the same urban area, which was considered an acceptable precision. The present study further evaluates the model by comparing it with temperature measurements carried out in Singapore.

In contrast to the European cities where the model was previously evaluated, in Singapore, urban vegetation is often abundant, urban morphology is very heterogeneous, and air-conditioning systems usually run throughout the year. In addition, the lack of undeveloped surroundings makes it difficult to find a suitable reference weather station for the UWG. Together this makes Singapore a challenging case study to analyse the potential and limitations of the model.

\section{Model improvements}

The UWG was originally published in [14]. It is composed of four coupled modules (Fig. 2): the Rural Station Model (RSM), the Vertical Diffusion Model (VDM), the Urban Boundary-Layer (UBL) model and the Urban Canopy and Building Energy Model (UC-BEM).

The RSM is a rural canopy model that reads hourly values of meteorological fields measured at the rural site and calculates sensible heat fluxes, 
which are then provided to the VDM and the UBL model. The model is based on an energy balance at the soil surface. A transient heat diffusion equation is solved by finite differences representing the storage and release of heat from the ground.

The VDM reads air temperatures and velocities measured at the weather station, as well as sensible heat fluxes calculated by the RSM, and calculates vertical profiles of air temperature above the weather station by solving a heat diffusion equation, which are then provided to the UBL model.

The UBL model calculates air temperatures above the urban canopy layer from the vertical profiles of air temperature provided by the VDM and the sensible heat fluxes provided by the RSM and the UC-BEM. The model is based on an energy balance for a selected control volume inside the urban boundary layer.

The UC-BEM calculates urban canyon air temperature and humidity from radiation and precipitation data, air velocity and humidity measured at the weather station, and from the air temperature above the urban canopy layer calculated by the UBL model. The model is based on the Town Energy Balance (TEB) scheme [11] including its building energy model [18].

\subsection{Urban mapping}

The new version of the UWG allows the user to define different neighbourhood characteristics within a city. The interaction between neighbourhoods above the urban canopy layer is solved by extending the approach used in the UBL model within the UWG [19]. The temperature calculated for an upwind section of the UBL is used as the reference temperature for a downwind section. Likewise, for the buoyancy-driven problem (i.e. the air movement is not provoked by geostrophic wind but by the urban breeze circulation), the temperature of the UBL at the periphery of the city is used as the reference temperature for the central area of the city.

The simulation procedure is as follows. All possible wind directions are divided into four quadrants (north, west, south and east). At each weather data time-step (depending on the available observational data), the model identifies upwind and downwind neighbourhoods as a function of neighbourhood adjacency and wind direction. For example, if the wind is coming from the north, neighbourhoods assigned to northwest, north and northeast will be upwind, neighbourhoods assigned to west, centre and east will be downwind of the first group, and neighbourhoods assigned to southwest, south and southeast will be downwind of the second group. For the first group (the 
one upwind), the model calculates the average boundary layer air temperature and passes it as reference temperature to the second group. The same procedure is carried out for the second and third groups. If the first group is empty for a certain wind direction (e.g. no neighbourhoods assigned to northwest, north or northeast in our example), the next group containing the centre neighbourhood is established as the first group. The model does not impose size restrictions on the different neighbourhoods. Therefore, the user should be aware that the model is taking the reference air temperature for a particular neighbourhood as that of the upwind neighbourhoods independently of their size.

\subsection{Specification of building uses}

Previous versions of the model only allowed the definition of one building type per neighbourhood (i.e. one building use, one specification of materials and construction, etc.). However, the reality is quite different, with various building usages and features in one neighbourhood or even one building. The new version of the model allows the definition of a building usage distribution for each neighbourhood (e.g. 20\% commercial, $20 \%$ residential with air-conditioning systems, $60 \%$ residential without air-conditioning systems). The energy performance of each building type within a neighbourhood is simulated separately in parallel. All building types in a neighbourhood are affected by the same urban climate (that of the neighbourhood) and their effect on the urban climate is weighted according to the building usage distribution. The goal is a better estimation of building energy consumption at the urban scale and sensible heat fluxes released into the environment. This new feature adds flexibility to the model and improves the representation of real situations with mixed building usage within a neighbourhood.

\subsection{Improved urban boundary layer submodel}

The UBL submodel solves an energy balance for a control volume above the urban canopy layer for which boundary conditions can be imposed [19]. It considers the UBL as a region of well-mixed, isothermal air below a capping inversion which is lower during nighttime compared to during the day.

The water vapour and carbon dioxide contained in the UBL air absorb and emit longwave radiation, so these effects must be included in the model. In a practical engineering application such as the UBL model, and under a number of simplifying assumptions (detailed below), it is possible to evaluate 
the total longwave radiation emission and absorption of the air based on emissivities [20].

The UBL submodel uses the correlations of Leckner [21] based on wideband radiation models, which calculate the total emissivity and absorptivity (including the whole spectrum) of a homogeneous gas from a few known inputs (temperature, partial pressure of the participating gases, total pressure and geometric path).

Figure 3 shows the strong dependence of air emissivity and absorptivity on temperature and the urban boundary layer depth obtained from Leckner's correlations. It can be seen that, for surface temperatures relatively close to the air temperature, the absorptivity of the air almost equals the emissivity.

At daytime, the net longwave radiation in the UBL control volume is approximated to the incoming radiation measured by a pyrgeometer at the reference weather station. On the other hand, in order to solve for the net longwave radiation at nighttime, an isothermal, nonscattering, infinite slab of air confined between black walls is considered. The upper "surface" temperature, which represents an effective sky temperature above the UBL $\left(\theta_{\text {sky }}\right)$, is calculated from the incoming longwave radiation $(L \downarrow)$ according to the following expression:

$$
L \downarrow=(1-\alpha) \sigma \theta_{s k y}^{4}+\epsilon \sigma \theta_{u b l}^{4},
$$

where $\alpha$ and $\epsilon$ are the bulk absorptivity and emissivity of air in the control volume, respectively, $\sigma$ is the Stefan Boltzmann constant, and $\theta_{u b l}$ is the temperature of the control volume at the previous timestep. Assuming that the absorptivity equals the emissivity and linearizing the radiative heat transfer equation, the energy balance of the UBL submodel is now given by:

$V_{C V} \rho c_{v} \frac{d \theta_{u}}{d t}=H_{u}+\int u_{r e f} \rho c_{p}\left(\theta_{r e f}-\theta_{u}\right) d A_{f}+4 \epsilon \sigma \theta_{m}^{3}\left(\theta_{s k y}-\theta_{u}\right)+4 \epsilon \sigma \theta_{m}^{3}\left(\theta_{\text {surf }}-\theta_{u}\right)$,

where $V_{C V}$ is the control volume, $\rho$ is the air density, $c_{v}$ is the specific heat of air at constant volume, $c_{p}$ is the specific heat of air at constant pressure, $\theta_{u}$ is the average potential temperature of the control volume, $H_{u}$ is the sensible heat flux at the surface of the control volume [W], $\theta_{\text {ref }}$ is a reference potential temperature outside the control volume, $u_{r e f}$ is a reference air velocity, $A_{f}$ is the lateral area of heat exchange between the control volume and its surroundings, $A_{h}$ is the horizontal area of the control volume, 
$\theta_{m}$ in an average air temperature, and $\theta_{\text {surf }}$ is an effective surface temperature including roofs, roads, and the urban canopy air.

In addition, the new version of the UBL model numerically solves the advection integral (Eq. 2) by using the vertical profile of air temperature calculated by the vertical diffusion submodel within the UWG and a logarithmic profile for the wind speed.

\subsection{New formulation for the effects of surface roughness on flow}

A new formulation implemented in the UWG simplifies the representation of the effect of surface roughness on the airflow (i.e. the calculation of friction velocities). Previous versions of the model were based on the formulation of Louis [22], which includes various empirical parameters whose application to urban areas were not justified. The new model uses the formulation of Hanna and Britter [23], which is not based on data-fitting, was developed specifically for urban areas, and considers an engineering approach that is consistent with the UWG concept. A comprehensive description of this new formulation is presented in the Appendix.

\section{Evaluation with field data}

\subsection{Description of study area}

In this section, the new version of the UWG is compared with field data from a network of weather stations in Singapore. Singapore is a city-state island located at the southern tip of the Malay Peninsula, just north of the equator. The island experiences a typical wet tropical climate with uniformly high temperatures and abundant rainfall throughout the year. Seasons are characterized by the wind direction, differentiating between two distinctive monsoon periods. Moderately strong surface winds from the northeast characterise the winter months (December-March) whereas weaker southwest winds dominate during summer months (May-September). During the intermonsoon seasons, wind direction is highly variable and mean wind speeds are generally low.

This study uses weather data measured in February (northeast monsoon period) and in July (southwest monsoon period) of 2010. Temperature observations from eight ONSET HOBO ${ }^{T M}$ sensors (HOB-032-08) mounted on lampposts at about $2 \mathrm{~m}$ above the ground, representing a range of land uses, morphological parameters and building usages, are used in this analysis (Fig. 4). The sensors constitute part of a larger island-wide network and have been 
compared against each other before deployment to ensure relative accuracy of readings [25].

Fig. 5 shows wind roses from data measured by the Meteorological Service at Singapore Changi Airport during February and July (2010). The data clearly illustrate the typical features of each monsoon period in terms of wind direction and speed. Compared with the long-term monthly rainfall for February and July reported by Chow and Roth [26] (170 mm and $150 \mathrm{~mm}$, respectively), February 2010 was a particularly dry month, with monthly rainfall of $27 \mathrm{~mm}$ and mean relative humidity of $77 \%$, while July 2010 was a particularly rainy month, with $305 \mathrm{~mm}$ monthly precipitation and $85 \%$ relative humidity.

\subsection{Model set-up}

Figure 4 shows the location and sizes of the individual neighbourhoods defined in the model. The model domain has two regions: the eastern region between Paya Lebar Airbase and Changi Airport and the western region between Singapore's central water catchment area and Paya Lebar Airbase. In order to connect the northern and southern neighbourhoods in the western region, an intermediate area is defined in the model and simulated but not used in the discussion. This area would approximately correspond to Hougang district, and its modelling parameters are the same as for the northern neighbourhood.

The required morphological parameters were obtained by both manual and automated methods. Within a radius of $100 \mathrm{~m}$ from each of the sensors, detailed land use information was gathered from building footprint maps (OneMap.sg maintained by data.gov.sg) and satellite images (Digital Globe via Google Earth software). Each urban area is analysed using raster layers with cell resolutions of approximately $0.3 \mathrm{~m}$. The procedure of delineating the buildings was done by applying colour thresholds to the colour-coded building footprint raster layer, followed by manual cleaning to remove discrepancies. Tree-crowns were classified visually using a georeferenced satellite raster layer overlain on the building footprint layer (Fig. 6). As a result, the plan area density of buildings and vegetation can be calculated.

Subsequently, the perimeter of buildings in each site $\left(P_{b l d}\right)$ was obtained by automated image processing using a script employing the Gimp Library. As the virtual circular boundary passes through several buildings in each site, these artificial edges were also calculated so as to reduce the perimeter values to actual perimeter values in the real world. 
The vertical-to-horizontal built ratio $\left(V H_{u}\right)$ is then calculated as:

$$
V H_{u}=\frac{P_{b l d} h_{b l d}}{A_{u}},
$$

where $A_{u}$ is the plan area of the site and $h_{b l d}$ is the average building height, derived by averaging known (or estimated) heights of buildings in each site, normalized by the area of their individual footprints.

In addition, building usage distribution for each urban area was obtained from the Urban Redevelopment Authority Integrated Map System (http://www.ura.gov.sg/uramaps/). The resulting morphological and energy use parameters are summarized in Table 1. Given the impossibility of obtaining reliable indoor building parameters for the building stocks of the different urban sites, these parameters were chosen based on experience, differentiating between residential and commercial buildings (Table 2).

The building parameters required by the UWG are the typical ones for building energy simulations, including internal heat gains. Therefore, anthropogenic heat fluxes from building energy uses other than air-conditioning systems are inputs to the model, while anthropogenic heat fluxes from airconditioning operation are calculated by the model. Separating weatherdependent anthropogenic heat fluxes from the model inputs helps to identify suitable model parameters based on knowledge that has already been developed for building energy assessment applications.

The validity of the set of building parameters used in the UWG simulations is tested by comparing the anthropogenic heat introduced to and calculated by the model with a previous study that estimates this variable for similar neighbourhoods in Singapore [27]. This comparison is presented in section 3.3.

Other parameters used in the simulation are summarized in Table 3. Building materials for this case study are similar to those used in another paper that simulates the UHI effect in Singapore using a mesocale atmospheric model coupled with an urban canopy model [28]. These simulations were also used to estimate the nighttime and daytime boundary layer heights required as inputs in the UWG. The anthropogenic heat from traffic is also an input of the model and was obtained from Quah and Roth [27]. Values for the other model parameters were chosen as the best estimation, based on previous experiences with the model [19, 14].

The HOBO sensor located in Seletar Farmway (Fig. 4) is used as the reference site for air temperature in this study, taking advantage of the fact 
that this sensor was calibrated with the other HOBO sensors used in the analysis. Seletar Farmway is located in a non-urbanized area in the northeast of the island. It is a suitable location for winds coming from the north and northeast, considering the low height of the sensor $(\sim 2 \mathrm{~m})$, which makes readings less susceptible to influences from a small airport about $1 \mathrm{~km}$ to the north. However, the station may capture an urban signal for winds coming from the south given a residential area about $500 \mathrm{~m}$ away in that direction. Other meteorological variables, such as solar radiation, wind speed and direction, humidity, incoming longwave radiation, and precipitation were obtained from the Meteorological Service Singapore station located at Changi Airport.

\subsection{Verification of anthropogenic heat flux}

In urban climate studies, anthropogenic heat flux is defined as the heat released due to human activity that participates in the energy balance of the urban canopy [29]. This includes heat from vehicles and human metabolism, and the energy consumed in buildings, industry, street lighting and other urban activities.

In this section, the anthropogenic heat introduced to and calculated by the UWG (see Section 3.2) is compared with a study by Quah and Roth [27], hereafter referred to $A H$ Reference. They estimated the contributions to the anthropogenic heat flux from traffic, buildings, and human metabolism by using an inventory-based modelling approach for three urban neighbourhoods between October 2008 and March 2009 in Singapore. As stated before, the energy consumption of air-conditioning systems is the only component of anthropogenic heat directly calculated by the UWG. This comparison is then mainly used to justify the choice of building parameters used in the UWG simulations (Table 2), but it can also be understood as a first test of the capability of the UWG to estimate cooling energy consumption.

Table 4 compares the average daytime and nighttime anthropogenic heat flux obtained by the UWG with the average anthropogenic heat flux estimated in the $A H$ Reference. The comparison uses the same three building stock categories as in the $A H$ Reference, namely, commercial, high-density public housing and low-density residential. In the case of the UWG, the values correspond to the average results for February and July, 2010, for Bideford Rd, Punggol Field and Limau Grove, respectively.

The results show a reasonably good agreement between the UWG and the AH Reference. The choice of building parameters of the UWG leads to 
daytime and nighttime anthropogenic heat fluxes of $115 \mathrm{~W} \mathrm{~m}^{-2}$ and $61 \mathrm{~W}$ $\mathrm{m}^{-2}$ for the commercial area, similar to those of the AH Reference. Residential buildings show small variations between day and night, and the anthropogenic heat values range between $9 \mathrm{~W} \mathrm{~m}^{-2}$ and $33 \mathrm{~W} \mathrm{~m}^{-2}$ as calculated in the model and between $9 \mathrm{~W} \mathrm{~m}^{-2}$ and $14 \mathrm{~W} \mathrm{~m}^{-2}$ in $A H$ Reference. The fact that the anthropogenic heat calculated by the model for the residential urban areas is higher at nighttime than at daytime (while the opposite is true for the $A H$ Reference) can be explained by the constant internal heat gains considered in the UWG. The differences between model and inventory estimates shown in Table 4 for the same building stock category can also be explained by the fact that the urban areas considered in each study have different building densities and, therefore, different energy intensity per unit of urban area.

\subsection{Prediction of urban air temperature}

The capability of the UWG to predict urban air temperature is evaluated here. Fig. 7 compares the average diurnal cycle of urban air temperature calculated by the model with observations for February and July, 2010. The average and standard deviation of the seven urban sites are considered. The model overpredicts urban air temperatures during daytime in February and underpredicts nighttime air temperatures in July. Small jumps in the model results are evident during the night-day and day-night transition periods, especially in July. The UBL submodel inside the UWG solves two different sets of equations for night- and daytime, respectively, which may lead to discontinuities during the transition periods. These discontinuities are attenuated by the thermal inertia of the UBL air and can be further reduced by slightly modifying the shifting times between night and day.

The comparison leads to a Root Mean Square Error (RMSE) of $0.9 \mathrm{~K}$ in February and $1.2 \mathrm{~K}$ in July, with a measured daily-maximum temperature difference between the average urban temperature and the temperature measured at the reference site of $1.8 \mathrm{~K}$ in February and $2.5 \mathrm{~K}$ in July (Table 5 ). The Mean Bias Error (MBE) is $0.5 \mathrm{~K}$ in February and $-0.5 \mathrm{~K}$ in July. The average standard deviation calculated by the model is the same as the one from observations. An error (RMSE) of around $1 \mathrm{~K}$ obtained in the case of Singapore is similar to the one obtained for previous case studies, Basel and Toulouse, for which the new version of the model has also been tested. The performance of the UWG is comparable to the previously referred study [28] that, using a significantly more complex and computationally expensive 
simulation platform, achieves an average RMSE of $1.7 \mathrm{~K}$ when compared with the same set of temperature measurements.

Model performance for different weather conditions is shown in Fig. 8, which plots average hourly differences between simulated and observed temperatures at all seven urban stations and values from the reference station. The main difference between February and July periods is the number of rainy and clear days ( 7 rainy and 6 clear days in July vs 2 rainy and 14 clear days in February). However, a clear dependence of the model performance on the weather conditions cannot be inferred from Table 6, albeit based on a very small sample size.

Finally, Table 7 compares site-specific air temperatures calculated by the model with observations for each of the seven urban sites and for all weather conditions. The model is not able to significantly improve beyond the spatially-averaged results when applied to a particular urban site. When the average of canopy layer air temperatures calculated by the UWG are compared with the observed site-specific air temperatures, the average RMSE in February and July remains the same as when using the calculated site-specific air temperatures. The site-specific diurnal cycles are also similar to the average ones and, therefore, are not shown. The parameterizations included in the model are insufficient to capture very site-specific microclimate effects, which would require a numerical solution of the momentum equation, but robust enough to produce plausible values across urban morphology and vegetation parameters which vary by a factor of two or more. Nevertheless, the urban mapping capability of the model (see section 2.1) is still useful because it helps to define the morphological parameters of the different urban areas within a city and allows the analysis of the building energy consumption distribution in spatially heterogeneous cities.

\subsection{Discussion of the reference weather station}

The UWG reference weather station must capture the climate conditions upwind of the city for all wind directions. For this reason, reference weather stations should be situated in a location on the periphery of the city, which is not surrounded by urban land use and is not affected by site-specific microclimate conditions produced by orography or the presence of large water bodies. In many situations, however, available weather data can only be found in locations (e.g. airports) that may not satisfy these requirements. This is the

case of Singapore, for which it is difficult to find a suitable reference site because the city is mainly surrounded by the sea. 
Nevertheless, it can be shown that, even for such situations, the UWG can be used to obtain a robust estimation of the UHI effect. If one analyzes the energy balance of the UBL control volume (section 2.3), sensible heat flux is the dominant energy exchange during daytime. At night the net longwave radiation flux is gaining relative importance and is of equal magnitude to the sensible heat flux. Advective heat flux plays a minor role. This result points to the importance of the incoming longwave radiation as boundary condition of the model at night, rather than station air temperature. Given that longwave radiation measurements are less sensitive to microclimate effects than air temperature measurements, the choice of the reference weather station is not crucial for the model.

To illustrate this conclusion, the same simulations described in section 3.2 are run again by using the air temperature measured at Changi Airport as the reference. Comparing the statistical indices in Table 8 with those in Table 5 shows that this new set of simulations predicts similar urban air temperatures as before, although the average maximum temperature difference between the urban sites and the reference site is significantly lower.

Another consequence of the low influence of the advective heat flux on the UBL energy balance is that the UHI effect has only a small sensitivity to city size, which agrees with previous findings reported in the literature [30].

\subsection{Comparison between the old and new UWG versions}

This section discusses the differences between the version of the UWG published in [14] and the present version.

The previous UWG calculated the advection effect by analytically solving the integral of the advective term in Eq. 2. In order to simplify the mathematical formulation, linear vertical profiles of temperature and wind speed were assumed at nighttime at the rural site. This assumption is valid for the first few meters of the atmosphere but deviates from reality for larger nighttime boundary layer heights. The new version of the model uses the Vertical Diffusion Submodel of the UWG [19] to approximate the real profile of air temperature and assumes a logarithmic distribution for the vertical profile of wind speed (Eq. 6 in Appendix). The advection integral is then solved numerically. The new approach makes the underlying physics of the model more transparent and reliable without adding complexity.

In addition, the model now includes the longwave radiation exchange between the urban boundary layer air and the atmosphere, which was not taken into account before. This is a significant cooling effect in the energy 
balance of the urban boundary layer, which is balanced by the reduction of the advection effect that results from considering a logarithmic rather than linear wind profile.

The UWG was originally evaluated against field data from experiments carried out in Basel [16] and in Toulouse [17]. The simulation of these two case studies by the new UWG produces the results summarized in Table 9 . It can be concluded that the accuracy of the old and the new UWG versions as applied to homogeneous cities located in temperate climates is similar. An additional test is carried out by simulating the different urban sites of Singapore's case study with the old version. The results are presented in Table 10. Comparing them with those shown in Table 7, it can be seen that the changes made to the new version improve the average RMSE of the model by $0.24 \mathrm{~K}$ in February while they worsen this parameter by $0.03 \mathrm{~K}$ in July. This overall improvement is nevertheless small.

Bueno et al. [14] argued that the error of the model is within the range of air temperature variability observed in different locations within the same urban area, which was considered an acceptable precision. Therefore, the new model does not aim to improve the accuracy of the UWG but to make it more robust and physically sound while extending its capabilities in terms of neighbourhood definition. As a result, the UWG can now be used to estimate the UHI effect and building energy consumption at neighbourhood resolution.

\section{Conclusions}

The Urban Weather Generator (UWG) calculates urban canopy layer air temperatures by using meteorological information measured at a reference weather station and applying a computationally efficient methodology based on energy conservation principles. It can also be used as a bottom-up building stock model to estimate energy consumption at city scale. A new version of the model has been developed, expanding its capability to account for different neighbourhoods and building usage distributions within a city. Additional improvements include the representation of the longwave radiation exchange between the urban boundary layer air and the atmosphere and a new formulation for the surface roughness effect on the airflow.

The UWG had previously been evaluated with field data from Europeantype cities. In this study, urban air temperatures calculated by the model are compared with measurements from a network of temperature sensors in 
Singapore, which includes a wide range of urban configurations within the city. Additionally, Singapore provides a test of the model in a humid tropical climate.

The comparison shows an accuracy level of the model similar to the one obtained for the previous case studies for which the new version has also been tested. The fact that the location of the reference weather station does not have a major impact on the simulation results makes the UWG particularly robust. The model can be applied to different climates and urban configurations to obtain an estimation of the UHI effect. However, the simplifications and assumptions of the model prevent it from capturing very site-specific microclimate effects, particularly for highly heterogeneous urban sites.

The boundary-layer height, which is used as an input parameter in the UWG, depends on the urban sensible heat flux and advection (e.g. seabreeze strength for nighttime cases). Further developments of the model could explore parameterizations for these variables. In the present study, the boundary-layer height was obtained from mesoscale atmospheric simulations because no observations were available. The resulting value (around $80 \mathrm{~m}$ above the urban canopy layer) was higher than the value used in previous European case studies $(50 \mathrm{~m})$. This can be possibly justified by the greater anthropogenic heat fluxes obtained at night due to air-conditioning operation.

The performance of the UWG as a building stock model has been preliminarily tested by comparing anthropogenic heat fluxes with those estimated in a previous study. Still, further evaluation is required in order to assess the reliability of building energy consumption predictions at the urban scale. Finally, a closer look at the physics of the problem shows that, as a consequence of the low influence of the advective heat flux on the energy balance of the urban boundary-layer, the dependence of the UHI magnitude on city size is small.

\section{Appendix: Effects of surface roughness on the flow}

\section{Aerodynamic properties}

For the rural site, the surface roughness length, $z_{o}$, is assumed to be equal to 0.1 times the average vegetation height, $z_{\text {or }}=0.1 h_{r}$. The zero-plane displacement length is zero for low roughness heights. 
For urban areas, the following formulas for the roughness length $\left(z_{\text {ou }}\right)$ and zero-plane displacement length are used $\left(d_{u}\right)[23]$ :

$$
\begin{array}{r}
z_{\text {ou }}=\lambda_{f} h_{\text {bld }} \text { if } \quad \lambda_{f}<0.15 \\
z_{\text {ou }}=0.15 h_{\text {bld }} \text { if } \quad \lambda_{f} \geq 0.15 \\
d_{u}=3 \lambda_{f} h_{b l d} \quad \text { if } \quad \lambda_{f}<0.05 \\
d_{u}=\left(0.15+5.5\left(\lambda_{f}-0.05\right)\right) h_{b l d} \quad \text { if } \quad 0.05 \leq \lambda_{f}<0.15 \\
d_{u}=\left(0.7+0.35\left(\lambda_{f}-0.15\right)\right) h_{b l d} \quad \text { if } \quad 0.15 \leq \lambda_{f}<1
\end{array}
$$

where $h_{b l d}$ is the average building height and $\lambda_{f}$ is the frontal area index, which in the UWG is approximated as a function of the vertical-to-horizontal built ratio, $\lambda_{f}=V H_{u} / 4$.

Friction velocity

For the rural site, the friction velocity is calculated as:

$$
u_{* r}=\frac{k u_{m}}{\ln \left(z_{m} / z_{o r}\right)},
$$

where $k=0.4$ is the von-Karman constant and $u_{m}$ is the wind speed measured at a height $z_{m}=10 \mathrm{~m}$.

The vertical profile of wind speed at the rural site used in the urban boundary layer (UBL) model [19] is given by:

$$
u_{r}(z)=\frac{u_{* r}}{k} \ln \left(z / z_{o r}\right),
$$

At the urban site, the friction velocity is calculated as:

$$
u_{* u}=\frac{k u_{b}}{\ln \left(\left(z_{b}-d_{u}\right) / z_{o u}\right)},
$$

where $u_{b}$ is the wind velocity at the blending height (approximately the top of the roughness sublayer), $z_{b}=2.0 h_{b l d}$. $u_{b}$ is calculated as:

$$
u_{b}=u_{m} \frac{\ln \left(z_{\text {ref }} / z_{\text {or }}\right)}{\ln \left(z_{m} / z_{\text {or }}\right)} \frac{\ln \left(z_{b} / z_{\text {ou }}\right)}{\ln \left(z_{\text {ref }} / z_{\text {ou }}\right)},
$$


where $z_{\text {ref }}=150 \mathrm{~m}$.

In order to account for the air movement due to buoyancy forces, a convective scaling velocity, $w_{*}$, is used instead of the friction velocity when $w_{*}>u_{*}$. The convective scaling velocity is given by:

$$
w_{*}=\left(\frac{g H_{u} z_{r e f}}{\rho c_{p} T_{u}}\right)^{1 / 3},
$$

where $H_{u}$ and $T_{u}$ are the sensible heat flux and air temperature of the urban canopy. The modified friction velocity is then given by:

$$
u_{* \bmod }=\max \left(u_{*}, w_{*}\right)
$$

\section{Exchange velocity}

In the new version of the model, exchanges velocities $u_{e x}$ are proportional to the modified friction velocity (Eq. 11). $u_{* m o d}$ takes into account the increase in heat exchange between the urban canyon and the atmosphere for large urban sensible heat fluxes, avoiding the overprediction of urban canyon air temperature in those situations. This is expressed as:

$$
u_{e x}=C_{e x} u_{* \bmod },
$$

where $C_{e x}=0.3$ is a constant exchange velocity coefficient.

\section{References}

[1] M. Roth, Review of urban climate research in (sub)tropical regions, International Journal of Climatology 27 (2007) 1859-1873.

[2] B. B. Hicks, W. J. Callahan, M. A. Hoekzema, On the heat islands of washington, dc, and new york city, ny, Boundary-Layer Meteorology 135 (2010) 291-300.

[3] S.-H. Lee, J.-J. Baik, Statistical and dynamical characteristics of the urban heat island intensity in seoul, Theoretical and Applied Climatology 100 (2010) 227-237.

[4] Y. Zhou, J. Shepherd, Atlanta's urban heat island under extreme heat conditions and potential mitigation strategies, Natural Hazards 52 (2010) 639-668. 
[5] T. Houet, G. Pigeon, Mapping urban climate zones and quantifying climate behaviors - an application on toulouse urban area (france), Environmental Pollution 159 (2011) 2180 - 2192.

[6] A. Coutts, J. Beringer, N. Tapper, Changing urban climate and co2 emissions: Implications for the development of policies for sustainable cities, Urban Policy and Research 28 (2010) 27-47.

[7] E. Erell, T. Williamson, Intra-urban differences in canopy layer air temperature at a mid-latitude city, International Journal of Climatology 27 (2007) 1243-1255.

[8] D. J. Sailor, A review of methods for estimating anthropogenic heat and moisture emissions in the urban environment, International Journal of Climatology 31 (2011) 189-199.

[9] C. Grimmond, M. Roth, T. Oke, Y. Au, M. Best, R. Betts, G. Carmichael, H. Cleugh, W. Dabberdt, R. Emmanuel, E. Freitas, K. Fortuniak, S. Hanna, P. Klein, L. Kalkstein, C. Liu, A. Nickson, D. Pearlmutter, D. Sailor, J. Voogt, Climate and more sustainable cities: Climate information for improved planning and management of cities (producers/capabilities perspective), Procedia Environmental Sciences 1 (2010) $247-274$.

[10] J. Santiago, A. Martilli, A dynamic urban canopy parameterization for mesoscale models based on computational fluid dynamics reynoldsaveraged navier-stokes microscale simulations, Boundary-Layer Meteorology 137 (2010) 417-439.

[11] V. Masson, A physically-based scheme for the urban energy budget in atmospheric models, Boundary-Layer Meteorology 94 (2000) 357-397.

[12] H. Kusaka, H. Kondo, Y. Kikegawa, F. Kimura, A simple single-layer urban canopy model for atmospheric models: Comparison with multilayer and slab models, Boundary-Layer Meteorology 101 (2001) 329-358.

[13] A. Martilli, A. Clappier, M. W. Rotach, An urban surface exchange parameterisation for mesoscale models, Boundary-Layer Meteorology 104 (2002) 261-304. 
[14] B. Bueno, L. Norford, J. Hidalgo, G. Pigeon, The urban weather generator, Journal of Building Performance Simulation (2012b) 1-13.

[15] M. Kavgic, A. Mavrogianni, D. Mumovic, A. Summerfield, Z. Stevanovic, M. Djurovic-Petrovic, A review of bottom-up building stock models for energy consumption in the residential sector, Building and Environment 45 (2010) 1683 - 1697.

[16] M. W. Rotach, R. Vogt, C. Bernhofer, E. Batchvarova, A. Christen, A. Clappier, B. Feddersen, S.-E. Gryning, G. Martucci, H. Mayer, V. Mitev, T. R. Oke, E. Parlow, H. Richner, M. Roth, Y.-A. Roulet, D. Ruffieux, J. A. Salmond, M. Schatzmann, J. A. Voogt, Bubble an urban boundary layer meteorology project, Theoretical and Applied Climatology 81 (2005) 231-261.

[17] V. Masson, L. Gomes, G. Pigeon, C. Liousse, V. Pont, J.-P. Lagouarde, J. Voogt, J. Salmond, T. R. Oke, J. Hidalgo, D. Legain, O. Garrouste, C. Lac, O. Connan, X. Briottet, S. Lachérade, P. Tulet, The canopy and aerosol particles interactions in toulouse urban layer (capitoul) experiment, Meteorology and Atmospheric Physics 102 (2008) 135-157.

[18] Bueno, B., et al., 2012. Development and evaluation of a building energy model integrated in the TEB scheme. Geoscientific Model Development, 5 (2), 433-448.

[19] B. Bueno, J. Hidalgo, G. Pigeon, L. Norford, V. Masson, Calculation of air temperatures above the urban canopy layer from measurements at a rural operational weather station, J. Appl. Meteor. Climatol. 52 (2012a) 472-483.

[20] M. Modest, Radiative Heat Transfer, Chemical, Petrochemical \& Process, Academic Press, 2003. URL:

[21] B. Leckner, Spectral and total emissivity of water vapor and carbon dioxide, Combustion and Flame 19 (1972) 33 - 48.

[22] J.-F. Louis, A parametric model of vertical eddy fluxes in the atmosphere, Boundary-Layer Meteorology 17 (1979) 187-202.

[23] S. Hanna, R. Britter, Wind flow and vapor cloud dispersion at industrial and urban sites, number Bd. 1 in CCPS concept book, Center for 
Chemical Process Safety of the American Institute of Chemical Engineers, 2002. URL:

[24] L. Shashua-Bar, M. E. Hoffman, The green cttc model for predicting the air temperature in small urban wooded sites, Building and Environment 37 (2002) $1279-1288$.

[25] R. Li, Spatio-temporal dynamics of the urban heat island in singapore (master's thesis), 2013. National University of Singapore, Singapore.

[26] W. T. L. Chow, M. Roth, Temporal dynamics of the urban heat island of singapore, International Journal of Climatology 26 (2006) 2243-2260.

[27] A. K. Quah, M. Roth, Diurnal and weekly variation of anthropogenic heat emissions in a tropical city, singapore, Atmospheric Environment 46 (2012) $92-103$.

[28] X.-X. Li, T.-Y. Koh, D. Entekhabi, M. Roth, J. Panda, L. Norford, A multi-resolution ensemble study of a tropical urban environment and its interactions with the background regional atmosphere, Journal of Geographical Research (2013).

[29] T. Oke, Boundary layer climates, Methuen, 1987. URL:

[30] B. Atkinson, Numerical modelling of urban heat-island intensity, Boundary-Layer Meteorology 109 (2003) 285-310. 


\section{Tables}

Table 1: Morphological and energy use parameters for the neighbourhoods modelled by the UWG.

\begin{tabular}{|c|c|c|c|c|c|c|c|}
\hline Parameter & Punggol & PasirRis & Tampines & LimauGrove & Bideford & Penang & KimChens \\
\hline Characteristic length ( diagonal) $(\mathrm{km})$ & 4 & 3 & 3 & 3 & 1 & 1 & 1 \\
\hline Average building height $(\mathrm{m})$ & 26 & 36 & 36 & 9 & 26 & 15 & 10 \\
\hline Plan area density of buildings & 0.38 & 0.26 & 0.29 & 0.40 & 0.54 & 0.26 & 0.44 \\
\hline Vertical-to-horizontal built ratio & 1.55 & 1.75 & 1.66 & 0.80 & 1.64 & 0.58 & 0.83 \\
\hline Plan area density of vegetation (trees) & 0.19 & 0.28 & 0.14 & 0.12 & 0.19 & 0.43 & 0.15 \\
\hline Urban Usage: R-residential & $100 \% \mathrm{R}$ & $100 \% \mathrm{R}$ & $80 \% \mathrm{R}$ & $100 \% \mathrm{R}$ & $20 \% \mathrm{R}$ & $20 \% \mathrm{R}$ & $80 \% \mathrm{R}$ \\
\hline C-commercial & & & $20 \% \mathrm{C}$ & & $80 \% \mathrm{C}$ & $80 \% \mathrm{C}$ & $20 \% \mathrm{C}$ \\
\hline
\end{tabular}

Table 2: Building parameters for the neighbourhoods modelled by the UWG. Note that cooling setpoints are set higher than standard thermostat setpoints in order to account for non-air conditioned building surfaces such as corridors and restrooms. ACH stands for air changes per hour.

\begin{tabular}{lll}
\hline Building parameters & Commercial & Residential \\
\hline Internal heat gains & $10 \mathrm{~W} \mathrm{~m}^{-2}$ & $4 \mathrm{~W} \mathrm{~m}^{-2}$ (floor area) \\
Glazing ratio & 0.5 & 0.3 \\
Infiltration & $0.1 \mathrm{ACH}$ & $0.5 \mathrm{ACH}$ \\
Ventilation & $1.0 \mathrm{ACH}$ & $0.0 \mathrm{ACH}$ \\
Fraction of the building & & \\
stock using air-conditioning systems & $100 \%$ & $40 \%$ \\
Nighttime cooling setpoint & $303 \mathrm{~K}$ & $297 \mathrm{~K}$ \\
Daytime cooling setpoint & $300 \mathrm{~K}$ & - \\
Coefficient of performance of the cooling system & 2.5 & 2.5 \\
\hline
\end{tabular}


Table 3: Inputs and system parameters used in the UWG.

\begin{tabular}{|c|c|}
\hline Parameter & Setting \\
\hline Location & Singapore \\
\hline Latitude & $1.37^{\circ}$ \\
\hline Longitude & $103.98^{\circ}$ \\
\hline Reference weather data (air temperature) & Seletar Farmway $(1.3976,103.8658)$ \\
\hline Reference weather data (other variables) & Changi Airport $(1.3592,103.9894)$ \\
\hline Simulation period & $\begin{array}{l}\text { February } 1^{s t}-28^{t h}, 2010 \text { (northeast monsoon) } \\
\text { July } 1^{s t}-28^{t h}, 2010 \text { (southwest monsoon) }\end{array}$ \\
\hline \multicolumn{2}{|l|}{ Urban parameters } \\
\hline Anthropogenic heat from traffic & $\begin{array}{l}\text { Commercial } 10 \mathrm{~W} \mathrm{~m}^{-2} \text { (urban area) } \\
\text { Residential } 4 \mathrm{~W} \mathrm{~m}^{-2}\end{array}$ \\
\hline Building materials thermal conductivity & $0.67 \mathrm{~W} \mathrm{~m}^{-1} \mathrm{~K}^{-1}$ \\
\hline Building materials volumetric heat capacity & $1.2 \mathrm{e} 6 \mathrm{~J} \mathrm{~m}^{-3} \mathrm{~K}^{-1}$ \\
\hline Building albedo (roofs and walls) & 0.2 \\
\hline Road materials thermal conductivity & $1.0 \mathrm{~W} \mathrm{~m}^{-1} \mathrm{~K}^{-1}$ \\
\hline Road materials volumetric heat capacity & 1.6e $6 \mathrm{~J} \mathrm{~m}^{-3} \mathrm{~K}^{-1}$ \\
\hline Road albedo & 0.1 \\
\hline Window construction & Double pane clear glass \\
\hline Road low-vegetation fraction & 0.2 \\
\hline Daytime boundary-layer height & $700 \mathrm{~m}$ \\
\hline Nighttime boundary-layer height (above the urban canopy layer) & $80 \mathrm{~m}$ \\
\hline \multicolumn{2}{|l|}{ Reference weather station parameters } \\
\hline Vegetation fraction (the rest is road) & 0.73 \\
\hline Road materials thermal conductivity & $1.0 \mathrm{~W} \mathrm{~m}^{-1} \mathrm{~K}^{-1}$ \\
\hline Road materials volumetric heat capacity & $1.6 \mathrm{e} 6 \mathrm{~J} \mathrm{~m}^{-3} \mathrm{~K}^{-1}$ \\
\hline Road albedo & 0.1 \\
\hline
\end{tabular}


Table 4: Anthropogenic heat flux obtained by the UWG and reported in Quah and Roth [27] (AH Reference). UWG results correspond to the average results for February and July, 2010, for the urban areas of Bideford Rd (commercial), Punggol Field (high-density public housing) and Limau Grove (low density residential), respectively. AH Reference results correspond to the average of 181 days between October 2008 and March 2009 at Orchard Road (commercial), Clementi (high-density public housing) and Telok Kurau (low density residential) districts.

\begin{tabular}{llll}
\hline Anthropogenic heat flux $\left(\mathrm{W} \mathrm{m}^{-2}\right)$ & & UWG & AH Reference \\
\hline Commercial & Day & 115 & 108 \\
& Night & 61 & 52 \\
High-density public housing & Day & 17 & 14 \\
& Night & 33 & 10 \\
Low-density residential & Day & 9 & 12 \\
& Night & 16 & 9 \\
\hline
\end{tabular}

Table 5: Root mean square error (RMSE) and mean bias error (MBE) between the average of canopy layer urban air temperatures calculated by the UWG and observed at seven urban sites during February and July, 2010. Errors are compared to the average maximum temperature difference between the urban sites and the reference site $\left(\overline{\Delta T_{\max }}\right)$ observed during each period. The last two columns indicate the modelled and observed average standard deviation among the seven urban weather stations.

\begin{tabular}{cccccc}
\hline Month & RMSE $(\mathrm{K})$ & MBE $(\mathrm{K})$ & $\overline{\Delta T_{\max }}(\mathrm{K})$ & $\left.\overline{\sigma_{\text {mod }}}(\mathrm{K})\right)$ & $\overline{\sigma_{o b s}}(\mathrm{~K})$ \\
\hline February & 0.9 & 0.5 & 1.8 & 0.2 & 0.3 \\
July & 1.2 & -0.5 & 2.5 & 0.2 & 0.3 \\
\hline
\end{tabular}


Table 6: Root mean square error (RMSE) and mean bias error (MBE) between modelled and observed urban air temperatures for different weather conditions during the first 28 days of February and July, 2010. The last column indicates the number of days available for each weather type considered. A day is defined as be rainy if daily rainfall is greater than $10 \mathrm{~mm}$. Clear days are those without rain and when daily direct normal solar radiation is greater than $3500 \mathrm{~W} \mathrm{~h} \mathrm{~m}^{-2}$ in July and $5300 \mathrm{~W} \mathrm{~h} \mathrm{~m}^{-2}$ in February. Day and night are classified based on time, excluding 2 hours before and after each transition: daytime 9-17 LT and nighttime 21-5 LT. Weather data was measured by the Meteorological Service Singapore at Changi Airport.

\begin{tabular}{llccc}
\hline Condition & Month & RMSE $(\mathrm{K})$ & MBE $(\mathrm{K})$ & Num. days \\
\hline Rainy & February & 0.5 & 0.1 & 2 \\
Dry and clear & February & 1.0 & 0.6 & 14 \\
Rainy & July & 1.2 & -0.6 & 7 \\
Dry and clear & July & 1.0 & -0.3 & 6 \\
\hline Daytime & February & 1.0 & 0.6 & - \\
Nighttime & February & 0.8 & 0.4 & - \\
Daytime & July & 1.1 & -0.4 & - \\
Nighttime & July & 1.3 & -0.9 & - \\
\hline
\end{tabular}

Table 7: Root mean square error (RMSE) and mean bias error (MBE) between modelled and observed site-specific canopy layer urban air temperatures during the first 28 days of February and July, 2010.

\begin{tabular}{lcccc}
\hline & RMSE (K) & MBE (K) & RMSE (K) & MBE (K) \\
\hline Site & February & \multicolumn{3}{c}{ July } \\
\hline Punggol & 0.9 & 0.6 & 1.2 & -0.2 \\
Bideford Rd & 0.9 & 0.1 & 1.4 & -0.9 \\
Penang Rd & 1.0 & 0.4 & 1.1 & -0.3 \\
Kim Cheng Rd & 1.1 & 0.2 & 1.2 & -0.4 \\
Pasir Ris Dr & 1.3 & 0.9 & 1.3 & -0.5 \\
Tampines St & 1.1 & 0.7 & 1.3 & -0.5 \\
Limau Grove & 0.9 & 0.3 & 1.4 & -0.7 \\
\hline
\end{tabular}


Table 8: Same as Table 5 but using air temperatures from the Meteorological Service Singapore station located at Changi Airport as the reference.

\begin{tabular}{cccccc}
\hline Month & RMSE $(\mathrm{K})$ & MBE $(\mathrm{K})$ & $\overline{\Delta T_{\max }}(\mathrm{K})$ & $\left.\overline{\sigma_{\text {mod }}}(\mathrm{K})\right)$ & $\overline{\sigma_{o b s}}(\mathrm{~K})$ \\
\hline February & 0.9 & 0.6 & 1.2 & 0.2 & 0.3 \\
July & 0.8 & -0.2 & 1.0 & 0.2 & 0.3 \\
\hline
\end{tabular}

Table 9: Root mean square error (RMSE) and mean bias error (MBE) between modelled and observed average air temperatures in the urban boundary layer (UBL) and urban canopy layer (UCL). Periods correspond to the BUBBLE experiment (Basel) between 10 June and 10 July, 2002, and to the CAPITOUL experiment (Toulouse) in July of 2004. Results are calculated with the old and the new versions of the UWG.

\begin{tabular}{llcccc}
\hline & & RMSE (K) & \multicolumn{3}{c}{ MBE (K) } \\
& Site & old & new & old & new \\
\hline UBL & Toulouse & 0.8 & 0.9 & 0.2 & -0.1 \\
UCL & Toulouse & 0.7 & 0.8 & 0.2 & -0.2 \\
UBL & Basel & 0.9 & 0.8 & 0.2 & 0.1 \\
UCL & Basel & 0.9 & 1.1 & -0.6 & -0.7 \\
\hline
\end{tabular}

Table 10: Root mean square error (RMSE) and mean bias error (MBE) between modelled (with the old UWG version) and observed site-specific canopy layer urban air temperatures during the first 28 days of February and July, 2010.

\begin{tabular}{lcccc}
\hline & RMSE (K) & MBE (K) & RMSE (K) & MBE (K) \\
\hline Site & February & \multicolumn{3}{c}{ July } \\
\hline Punggol & 1.1 & 0.5 & 1.2 & 0.1 \\
Bideford Rd & 1.3 & 0.3 & 1.4 & -0.7 \\
Penang Rd & 1.3 & 0.8 & 1.1 & 0.2 \\
Kim Cheng Rd & 1.2 & 0.3 & 1.2 & -0.2 \\
Pasir Ris Dr & 1.6 & 1.0 & 1.3 & -0.1 \\
Tampines St & 1.3 & 0.6 & 1.3 & -0.2 \\
Limau Grove & 1.1 & 0.4 & 1.2 & -0.2 \\
\hline
\end{tabular}




\section{Figures}

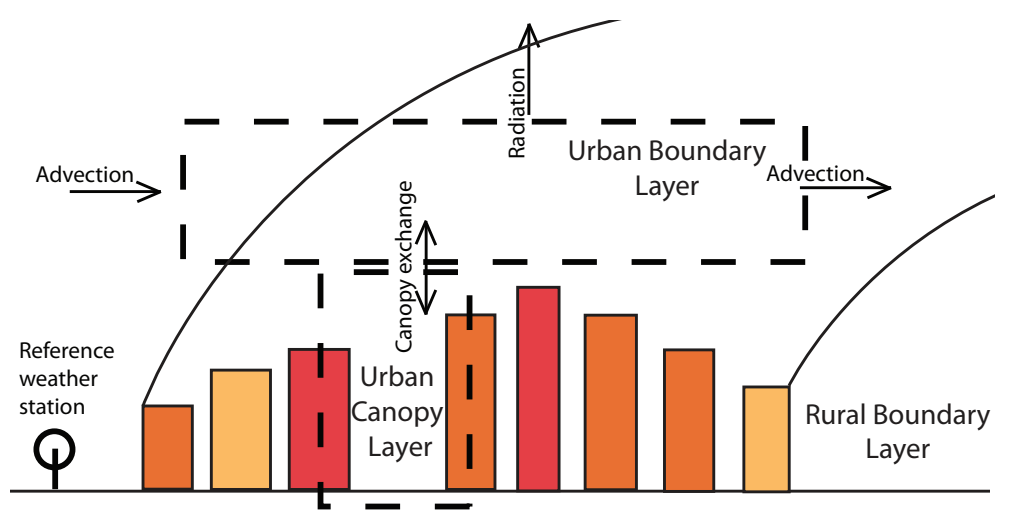

Figure 1: Representation of a city and the control volumes considered in the UWG. The model estimates the UHI effect in the city from meteorological information measured at a reference weather station upwind by applying energy conservation principles. 


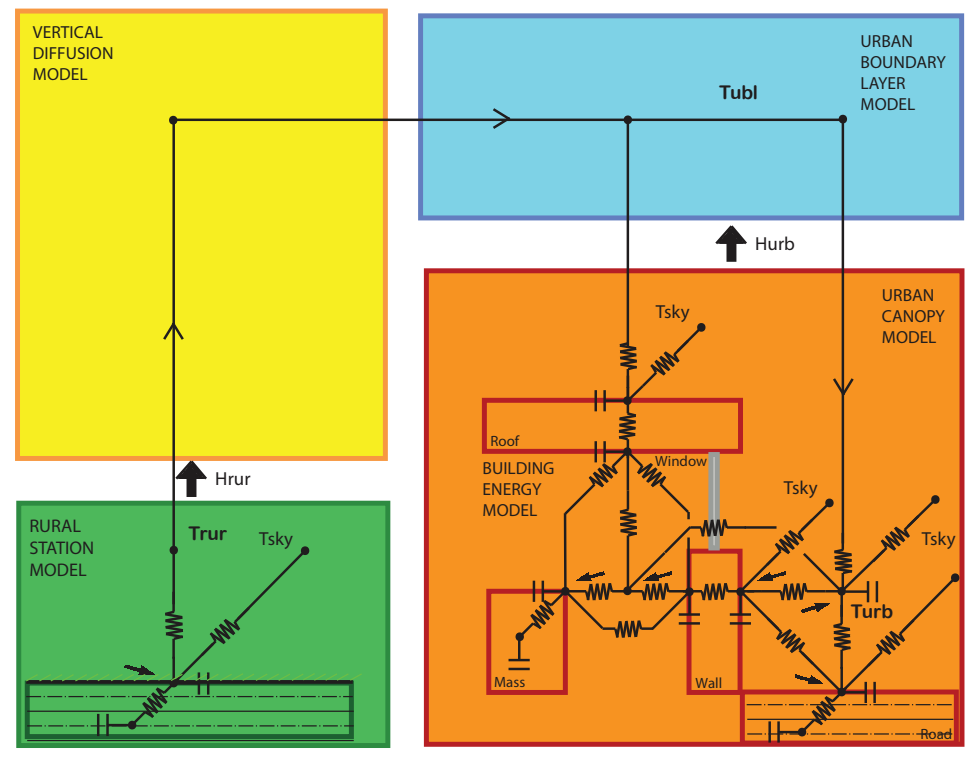

Figure 2: Diagram of the Urban Weather Generator (UWG) scheme, which is composed of four modules: the Rural Station Model (RSM), the Vertical Diffusion Model (VDM), the Urban Boundary-Layer (UBL) model, and the Urban Canopy and Building Energy Model (UC-BEM). Thermal networks indicate the main heat transfer processes included in the RSM and UC-BEM. $\mathrm{T}_{\text {rur }}, \mathrm{T}_{u b l}$, and $\mathrm{T}_{u r b}$ represent the air temperature measured at the weather station, calculated at the urban boundary layer, and calculated at the urban site. The RSM provides rural sensible heat fluxes $\left(\mathrm{H}_{\text {rur }}\right)$ to the VDM and the UBL model. The UC-BEM provides urban sensible heat fluxes $\left(\mathrm{H}_{u r b}\right)$ to the UBL model. 


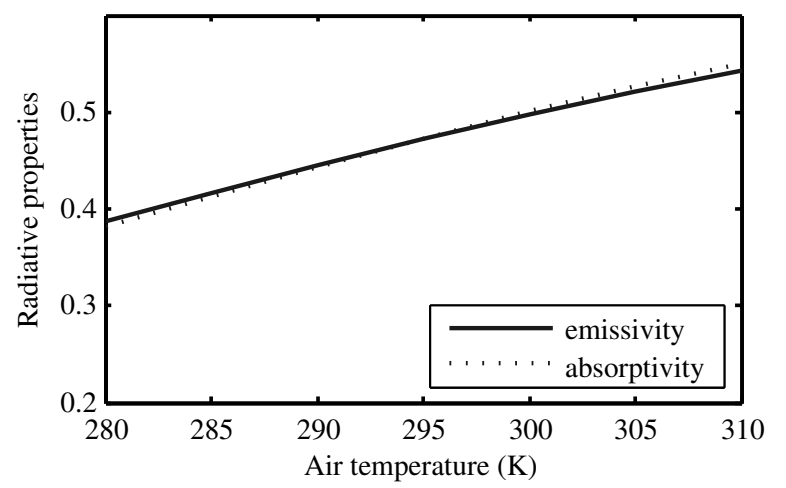

(a) Temperature

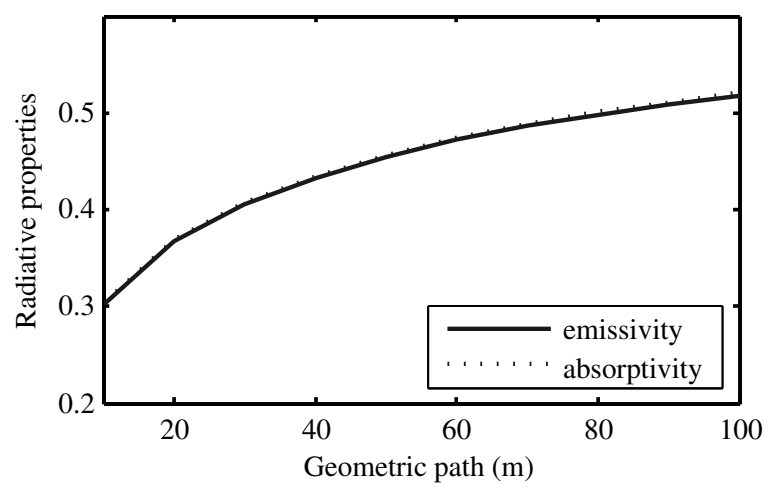

(b) Path

Figure 3: Dependence of emissivity and absorptivity of air on (a) temperature and (b) geometric path (from [21]). Calculations assume standard pressure, geometric path $80 \mathrm{~m}$ (a), air temperature $300 \mathrm{~K}$ (b), surface temperature $5 \mathrm{~K}$ below air temperature, $80 \%$ relative humidity, and $3.45 \cdot 10^{-4}$ volume fraction of $\mathrm{CO}_{2}$. 


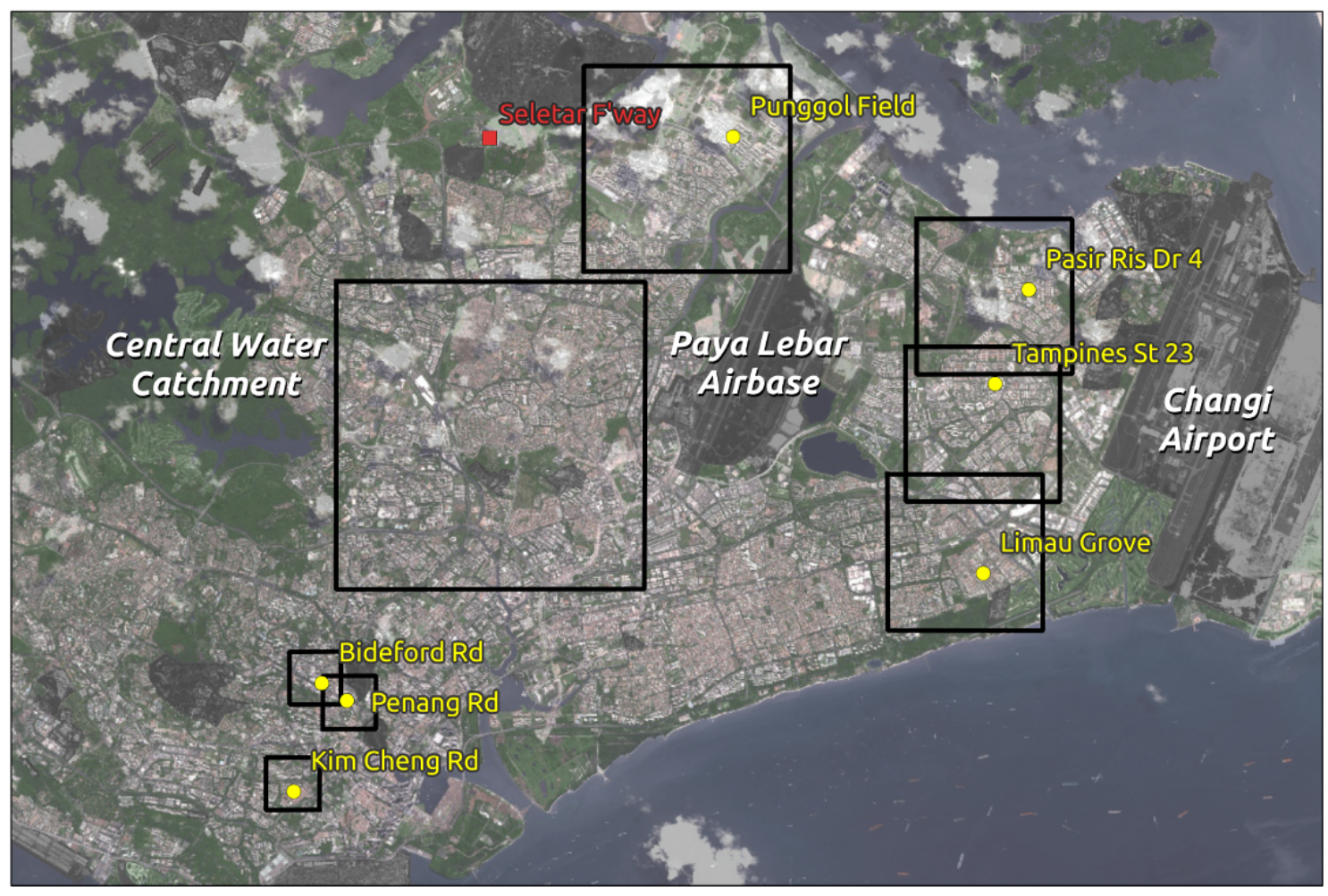

Figure 4: Map of the Eastern side of Singapore indicating the urban temperature stations (yellow dots) used in the analysis. Boxes indicate boundaries of the neighbourhoods represented in the model. 




(a) February

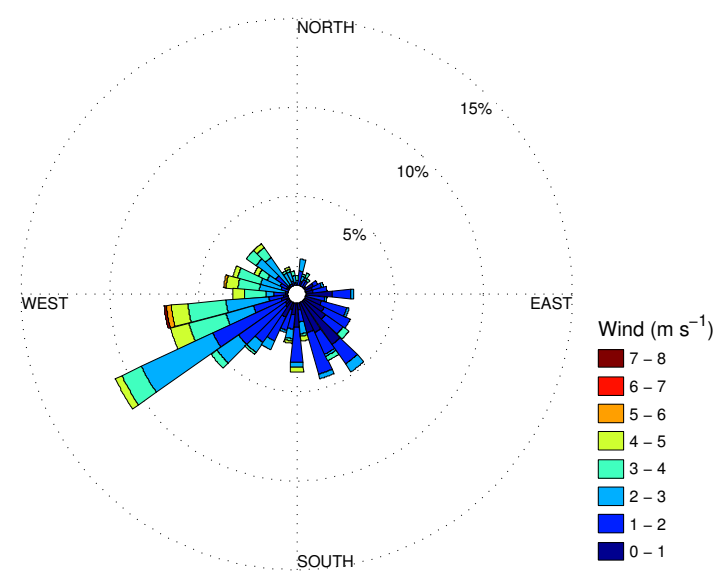

(b) July

Figure 5: Wind direction and speed measured by the Meteorological Service Singapore at Changi Airport during (a) February and (b) July (2010). 

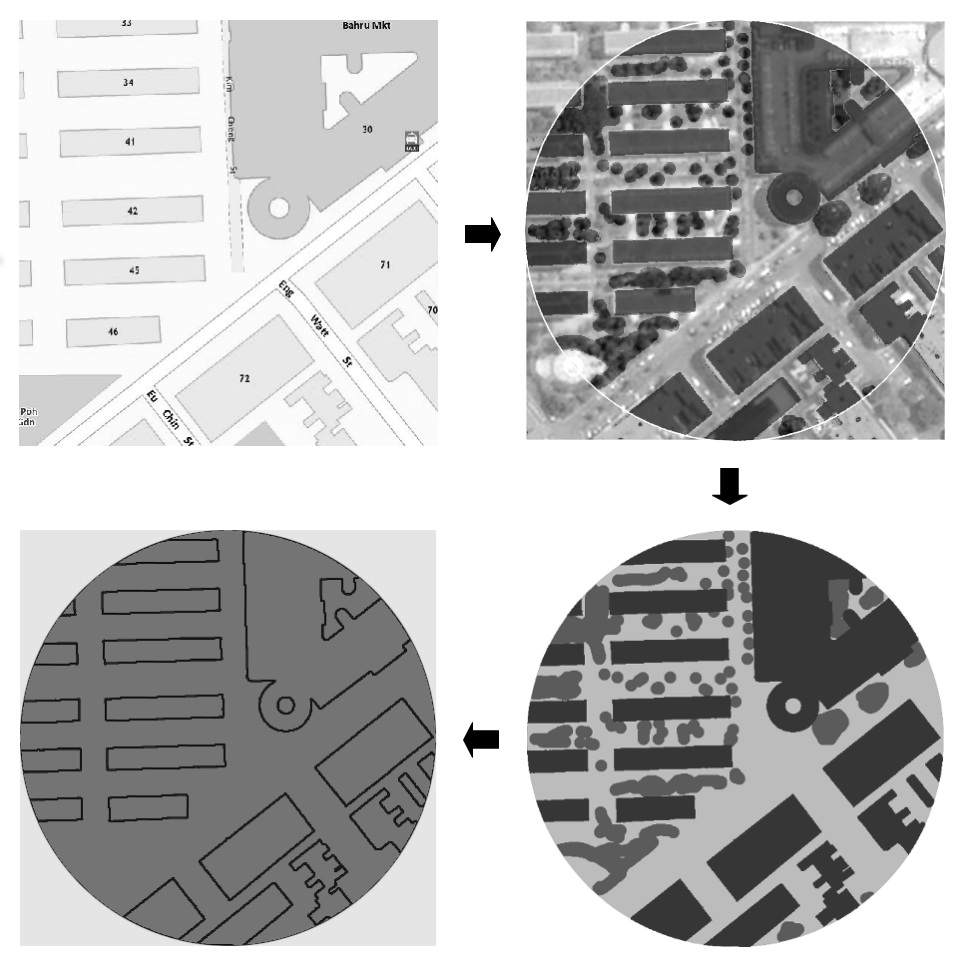

Figure 6: Workflow for obtaining values of urban and vegetation parameters for Kim Cheng. Clock wise from top-left: (i) Street map from OneMap.sg. (ii) Automated and manual classification of building footprints and vegetation using the OneMap.sg street map and satellite imagery from Google Earth. (iii) Cleaned-up output of the classification step. (iv) Perimeter of buildings extracted using a script. 


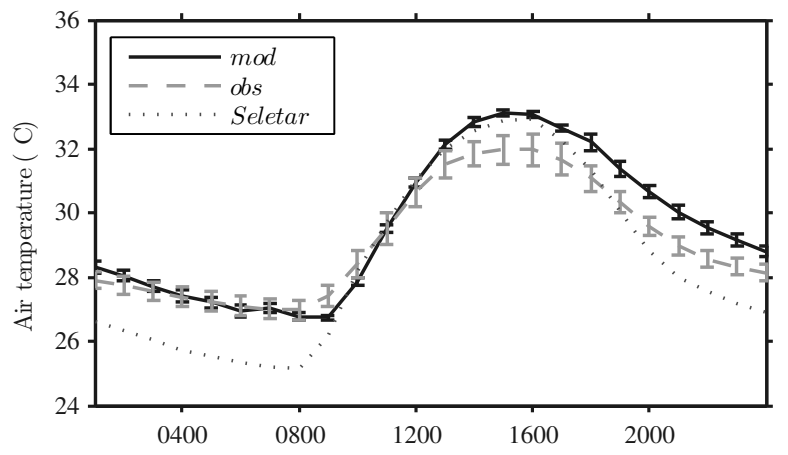

(a) February

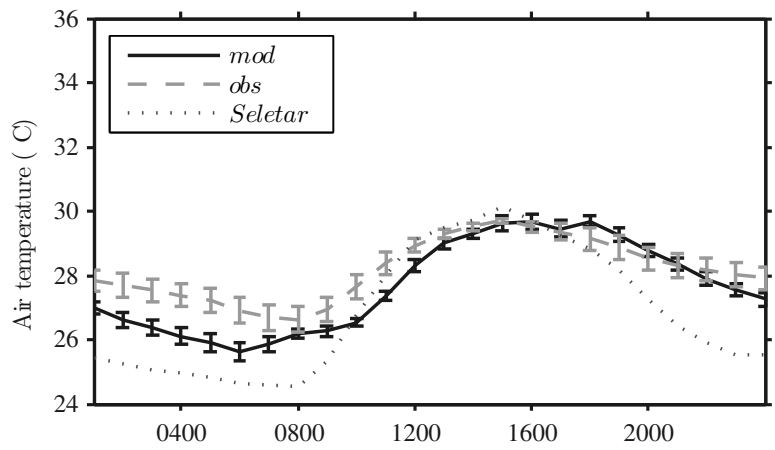

(b) July

Figure 7: Average diurnal cycle of canopy layer air temperature calculated by the UWG (mod) and observed (obs) in Singapore during (a) February and (b) July, 2010, for all weather conditions. Results correspond to the average of seven urban sites (Fig. 4). The error bar represents the standard deviation of simulated and measured air temperatures for the different sites. The air temperature measured at the reference weather station (Seletar Farmway) is also plotted to visualize the UHI effect. Hours in LT. 


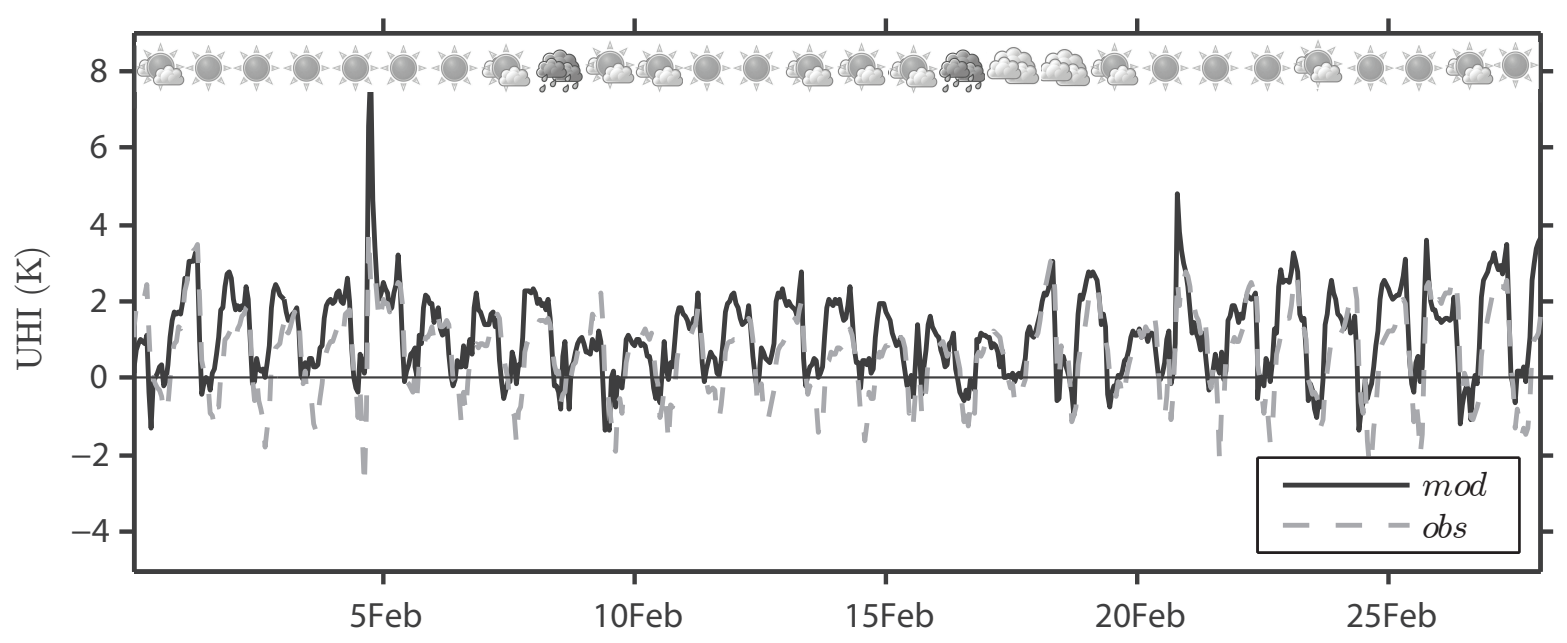

(a) February

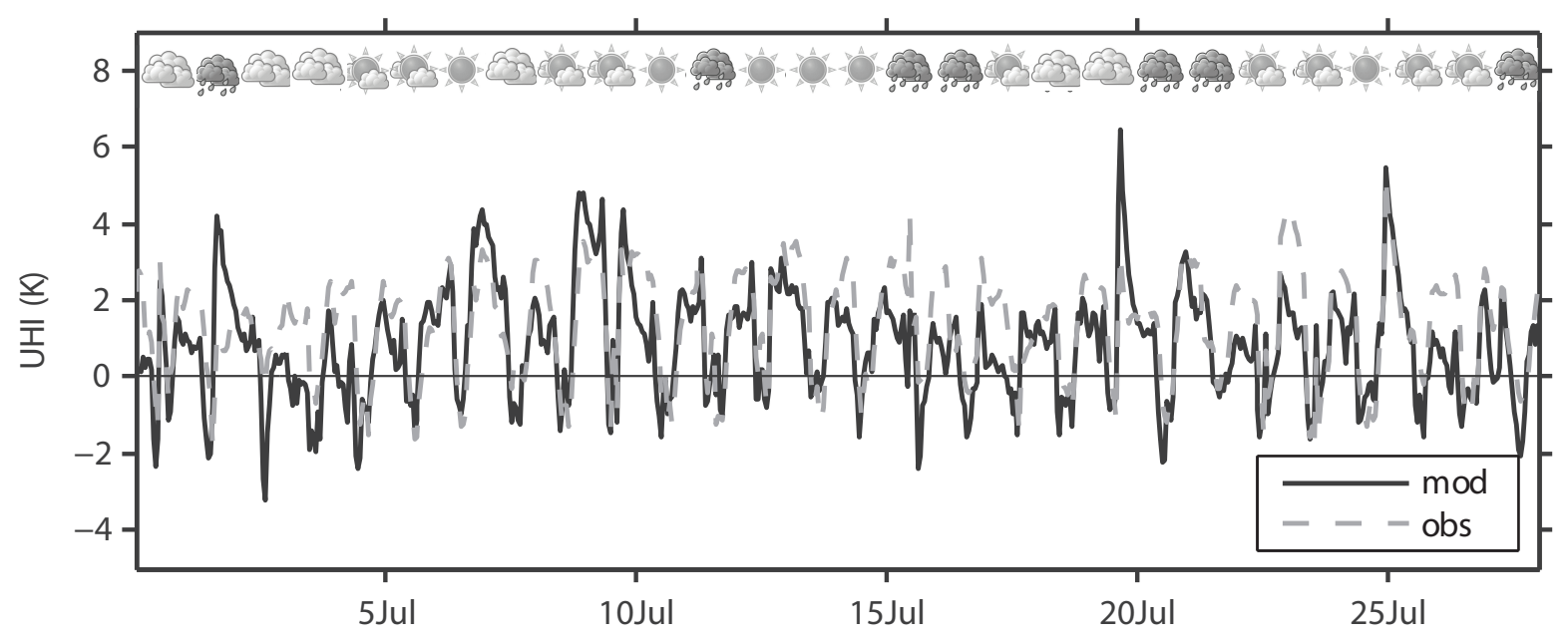

(b) July

Figure 8: Hourly canopy layer temperature difference between average of model simulations (mod) and observations (obs) for seven urban sites and the reference site for the first 28 days of (a) February and (b) July, 2010. Rainy days, dry and cloudy days, and dry and clear days are differentiated. 